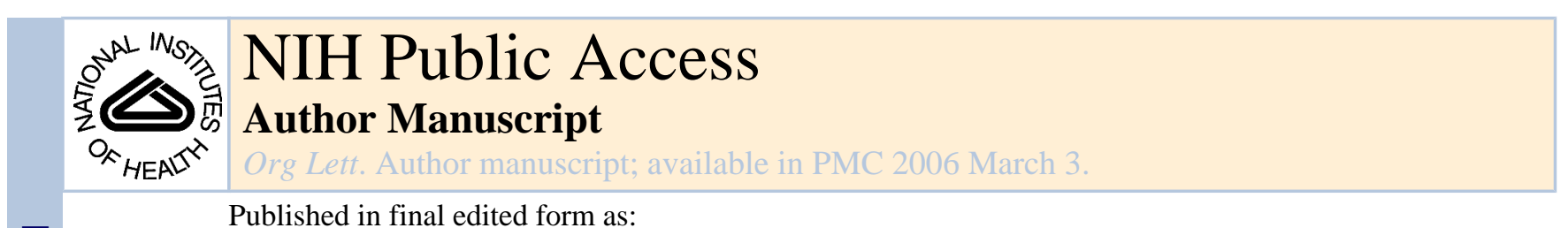

Org Lett. 2005 August 18; 7(17): 3621-3624.

\title{
Synthesis of the Branched $C$-Glycoside Substructure of Altromycin B
}

\author{
Bonsuk Koo and Frank E. McDonald \\ Department of Chemistry, Emory University, Atlanta, Georgia 30322
}

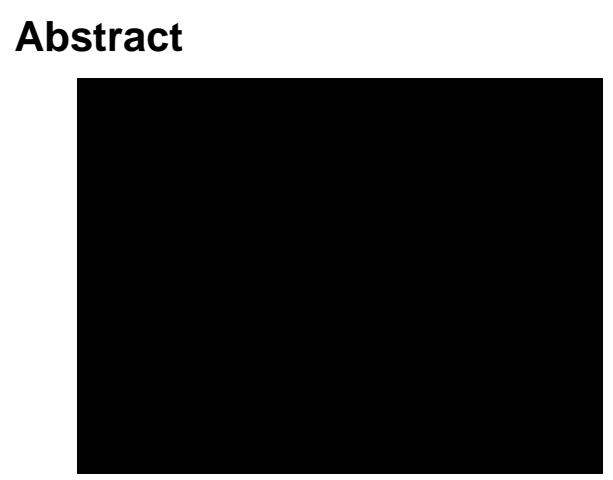

Tungsten-catalyzed cycloisomerization of alkynyl alcohols including 8 provides only the endocyclic enol ether (11) as a key intermediate for the branched $C$-glycoside substructure (2) of altromycin B. A sequence of Stille cross-coupling reaction and regio- and stereoselective functional group transformations affords each C13-diastereomer of the branched $C$-arylglycoside (2a and 2b).

\begin{abstract}
Altromycin B (1, Figure 1), a member of the family of pluramycin antibiotics isolated from a South African bushveld soil, was first reported to have selective antibiotic activities against Gram-positive bacteria in the early 1990s and later reported to possess anticancer activity including in vivo activity against P388 leukemia, as well as colon, lung, and ovarian tumors. ${ }^{1}$ The structure of altromycin B has been elucidated primarily by NMR spectroscopy, and thus the absolute stereochemistry of each of the widely separated chiral subunits has not been unambiguously assigned. Along with the studies on the biological activities, interactions between altromycin B with $\mathrm{DNA}^{2}$ and its metal complex ${ }^{3}$ have been reported. Despite the attractive biological activity of altromycin $\mathrm{B}$ and various congener natural products, none of the altromycin natural products have been prepared by total synthesis. Pasetto and Franck recently reported the synthesis of both possible $\mathrm{C} 13$ isomers $(\mathbf{2 a}, \mathbf{2 b})$ of the northwest quadrant of altromycin B, beginning with $\mathrm{D}-$ glucose. ${ }^{4}$ However, their efforts to assign $\mathrm{C} 13$ stereochemistry on the basis of the NMR comparison of their synthetic compounds 2a and 2b with altromycin B (1) were unsuccessful because of the complexity of the natural product structure. In support of our ongoing studies directed at the total synthesis of altromycins, we report herein a different synthesis of substructures $\mathbf{2 a}$ and $\mathbf{2 b}$ arising from non-carbohydrate precursors. 5
\end{abstract}

Our retrosynthetic analysis of $\mathbf{2 a}$ and $\mathbf{2 b}$ (Figure 1) envisioned a cross-coupling reaction 6 to form the C13 1,1-methylene linking the carbohydrate and aglycone sectors in $\mathbf{3}$, with the

fmcdona@emory.edu

Supporting Information Available: Experimental procedures and characterization data for new compounds, including data in CIF format. This material is available free of charge via the Internet at http://pubs.acs.org. 
carbohydrate coupling product $\mathbf{4}$ arising from the product of tungsten-catalyzed alkynol cycloisomerization of $\mathbf{5} .7$

Our synthesis began with the known diol 6 (Scheme 1). ${ }^{7 a}$ We observed regioselective formation of the methyl ether from the propargylic alcohol using cyclic stannylene activation of the diol, followed by silylation of the remaining alcohol and removal of the benzoate protective group with DIBAL reduction to afford alkynyl alcohol 7. Alternatively, protection of diol 6 with 2,2-dimethoxypropane in the presence of catalytic $p$-TsOH, followed by DIBAL reduction of the benzoate ester provided the cyclic acetonide-protected alkynol $\mathbf{8}$.

The tungsten-catalyzed cycloisomerization was initially conducted with substrate 7 (Table 1). In contrast to other alkynol substrates explored in our laboratory, the preparation of sixmembered glycal 9 could be optimized to provide only $33 \%$ yield. The crude ${ }^{1} \mathrm{H}$ NMR spectrum of the product mixture suggested the formation of a minor amount of the exocyclic methylene regioisomer 10, but this byproduct could not be isolated. ${ }^{8}$ However, cycloisomerization of the acetonide-protected substrate $\mathbf{8}$ gave better results. After optimization of the tertiary amine base and choice of solvent, ${ }^{9}$ we obtained glycal $\mathbf{1 1}$ as the only regioisomeric product in good isolated yield.

Glycal 11 with the acetonide protective group also proved ideal for conversion into the stannylated glycal 13 (Scheme 2), due to the tolerance of the acetonide upon reaction with tert-butyllithium as well as solubility for subsequent transformations, relative to silyl ether protected glycals including 9. Although the Stille cross coupling reaction between $\mathbf{1 3}$ and $\alpha$ iodostyrene was initially irreproducible under the usual conditions recommended for stannyl glycal partners, ${ }^{10}$ especially on millimole scales, the synergistic effect of copper-(I) salts and fluoride ion ${ }^{11}\left[\mathrm{Pd}\left(\mathrm{PPh}_{3}\right)_{4}(2 \mathrm{~mol} \%), \mathrm{CuI}(10 \mathrm{~mol} \%), \mathrm{CsF}\left(2\right.\right.$ equiv), DMF, $\left.45^{\circ} \mathrm{C}\right]$ provided a robust solution for this important transformation in our synthesis, affording C13-disubstituted diene 14 in $66 \%$ yield. ${ }^{12}$ Dihydroxylation ${ }^{13}$ of 14 using AD-mix $\alpha$ or $\beta$ regioselectively occurred at the less-substituted alkene and produced a separable mixture of diastereomers 15a and 15b (15a:15b $=0.9: 1$ with $A D-\operatorname{mix} \alpha ; 3.6: 1$ with $A D$-mix $\beta)$.

Treatment of diol 15a with borane.THF followed by $\mathrm{NaOH} / \mathrm{H}_{2} \mathrm{O}_{2}$ oxidation provided triol 16 in $75 \%$ yield (Scheme 3), with stereochemistry of $\mathbf{1 6}$ consistent with sterically controlled addition of borane to the convex face of the acetonide-protected glycal 15a. However, the other diastereomer $\mathbf{1 5 b}$ produced a hydroxyl group syn to the adjacent acetonide protected group as the major product under the same reaction conditions. We postulate that the primary C19alcohol may be directing the stereochemistry of hydroboration, ${ }^{14}$ since the mono-TBS ether $\mathbf{1 7}$ provided the expected stereoisomer 18 consistent with sterically controlled addition.

Compounds 16 and 18 were separately treated with TBSCl and imidazole to afford bis-TBSprotected compounds 19a and 19b, for which the primary alcohols were then selectively deprotected with catalytic CSA to provide $20 \mathbf{a}$ and 20b. 15

The synthesis of the altromycin branched glycoside substructure $\mathbf{2 a}$ was completed from diol 20a, beginning with Parikh-Doering oxidation followed by $\mathrm{I}_{2} / \mathrm{KOH}$ oxidation of the intermediate aldehyde to the methyl ester 21a (Scheme 4). ${ }^{16}$ Sequential removal of acetonide and silyl ether protective groups resulted in only trace formation of the tetraolmethyl ester 22a but rather the bicyclic lactone 23a as the major product. The rigidity of the fused bicyclic structure differentiated the remaining secondary alcohols of 23a so that the C4' equatorial alcohol was regioselectively converted into the methyl ether $\mathbf{2 4 a}$ via the cyclic stannylene intermediate. ${ }^{17}$ Opening of the lactone to the methyl ester of target compound 2a was initially accomplished by acidic methanolysis (Amberlyst-15, $\mathrm{MeOH}$ ), but better yields were consistently obtained under basic conditions. ${ }^{18}$ An identical series of transformations was conducted from the diastereomeric diol $\mathbf{2 0 b}$ to provide $\mathbf{2 b}$. 
The $\mathrm{C} 13$ hydroxyl stereochemistry was confirmed by X-ray crystallography of intermediate 23b, and NOE studies with diastereomer 23a allowed unambiguous stereochemical assignments for all synthetic products. ${ }^{19}$ The ${ }^{1} \mathrm{H}$ NMR spectra for our synthetic compounds 2a and $\mathbf{2 b}$ matched the data published by Pasetto and Franck for these two compounds. ${ }^{4}$

In combination with concurrent research into the synthesis of the altromycin aglycone, ${ }^{5}$ further studies directed toward the total synthesis of the altromycin natural products are in progress.

\section{Supplementary Material}

Refer to Web version on PubMed Central for supplementary material.

\section{Acknowledgment}

We thank the National Institutes of Health (CA 59703) for support of this research. We also acknowledge use of shared instrumentation provided by grants from the National Institutes of Health, National Science Foundation, and the Georgia Research Alliance (NMR spectroscopy, mass spectrometry, X-ray diffractometry) as well as the University Research Committee of Emory University (polarimeter). We also appreciate the work of Dr. Kenneth I. Hardcastle and Mr. Xikui Fang for crystal structure determinations of 23b and 24b

\section{References}

1. (a) Jackson M, Karwowski JP, Theriault RJ, Hardy DJ, Swanson SJ, Barlow GJ, Tillis PM, McAlpine JB. J. Antibiot 1990;43:223. [PubMed: 2324007] (b) Brill GM, McAlpine JB, Whittern DN, Buko AM. J. Antibiot 1990;43:229. [PubMed: 2324008]

2. (a) Sun D, Hansen M, Clement JJ, Hurley LH. Biochemistry 1993;32:1068. (b) Hansen M, Hurley L. J. Am. Chem. Soc 1995;117:2421. (c) Hansen M, Yun S, Hurley L. Chem. Biol 1995;2:229. [PubMed: 9383425] (d) Nakatani K, Okamoto A, Matsuno T, Saito I. J. Am. Chem. Soc 1998;120:11219.

3. (a) Menidiatis C, Methenitis C, Nikolis N, Peumatikakis G. J. Inorg. Biochem 2004;98:1795. [PubMed: 15522407] (b) Nikolis N, Methenitis C, Pneumatikakis G. J. Inorg. Biochem 2003;95:177. [PubMed: 12763663] (c) Nikolis N, Methenitis C, Pneumatikakis G, Fiallo ML. J. Inorg. Biochem 2002;89:131. [PubMed: 11931973]

4. Pasetto P, Franck RW. J. Org. Chem 2003;68:8042. [PubMed: 14535781]

5. Fei Z, McDonald FE. Org. Lett 2005;7:3617. [PubMed: 16092833]For synthesis of the altromycin aglycone substructure, see the preceding communication

6. (a) Stille JK. Angew. Chem., Int. Ed. Engl 1986;25:508. (b) Stille JK. Pure Appl. Chem 1985;57:1771.

7. (a) McDonald FE, Reddy KS, Díaz Y. J. Am. Chem. Soc 2000;122:4304. (b) McDonald FE, Reddy KS. Angew. Chem., Int. Ed 2001;40:3653. (c) Alcázar E, Pletcher JM, McDonald FE. Org. Lett 2004;6:3877. [PubMed: 15469372]

8. Wipf P, Graham TH. J. Org. Chem 2003;68:8798. [PubMed: 14604347]Wipf and Graham have also noted substituent effects on regioselectivity of this transformation

9. (a) Iwasawa N, Maeyama K, Kusama H. Org. Lett 2001;3:3871. [PubMed: 11720557]Iwasawa has observed dramatic solvent effects on the regioselectivity of mechanistically related tungsten carbonylpromoted carbacyclizations (b) Kusama H, Yamabe H, Iwasawa N. Org. Lett 2002;4:2569. [PubMed: 12123378] (c) Maeyama K, Iwasawa N. J. Am. Chem. Soc 1998;120:1928.

10. (a) MacLeod D, Moorcroft D, Quayle P, Dorrity MRJ, Malone JF, Davies GM. Tetrahedron Lett 1990;31:6077. (b) Abas A, Beddoes RL, Conway JC, Quayle P, Urch CJ. Synlett 1995;12:1264.

11. (a) Mee PH, Lee V, Baldwin JE. Angew. Chem., Int. Ed 2004;43:1132.For effect of Cu(I) in the Stille cross-coupling reaction, see (b) Liebeskind LS, Fengl RW. J. Org. Chem 1990;55:5359. (c) Kapadia VFS, Krishnan B, Wang C, Liebeskind LS. J. Org. Chem 1994;12:1047. (d) Casado AL, Espinet P. Organometallics 2003;22:1305. (e) Han X, Stoltz BM, Corey EJ. J. Am. Chem. Soc 1999;121:7600.

12. In all cases formation of the undesired homodimerization byproduct from glycal $\mathbf{1 3}$ could not be completely suppressed (ca. $20 \%$ yield). The attempted Stille cross coupling reaction with the bisTBS-protected stannyl glycal corresponding to $\mathbf{1 3}$ was unsuccessful, perhaps as a result of the poor solubility of this stannylated glycal in DMF. 
13. (a) Kolb HC, VanNieuwenhze MS, Sharpless KB. Chem. Rev 1994;94:2483.(b)Stereochemical assignments for $\mathbf{1 5 a}$ and $\mathbf{1 5} \mathbf{b}$ are based on conversions to bicyclic lactones 23a and 23b, respectively.

14. (a) Evans DA, Fu GC, Hoveyda AH. J. Am. Chem. Soc 1988;110:6917.Transition metal catalyzed hydroborations (b) Evans DA, Fu GC. J. Am. Chem. Soc 1991;113:4042. (c) Smith AB III, Yokoyama Y, Huryn DM, Dunlap NK. Tetrahedron Lett 1987;28:3659.An unsuccessful attempt to achieve hydroxyl-directed hydroboration has been reported

15. Paterson I, Florence GJ, Gerlach K, Scott JP, Sereinig N. J. Am. Chem. Soc 2001;123:9535. [PubMed: 11572673]

16. (a) Parikh J, Doering W. J. Am. Chem. Soc 1967;89:5505. (b) Yamada S, Morizono D, Yamamoto K. Tetrahedron Lett 1992;33:4329.Chromium(VI) oxidations resulted in oxidative cleavage of the C13-C19 bond

17. Grindley TB. Adv. Carbohydr. Chem. Biochem 1998;53:17. [PubMed: 9710969]

18. (a) Kamenecka TM, Danishefsky SJ. Chem. Eur. J 2001;7:41. (b) Anand RC, Selvapalam N. Synth. Commun 1994;24:2743.

19. See Supporting Information for NOE studies on 23a, as well as crystallographic information for 23b and 24b. 


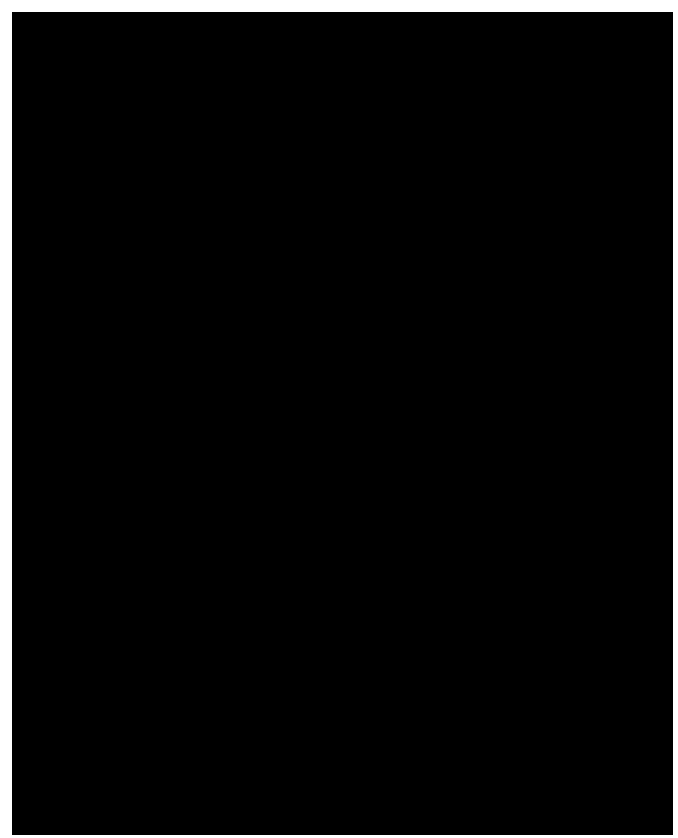

Figure 1.

Retrosynthetic analysis. 


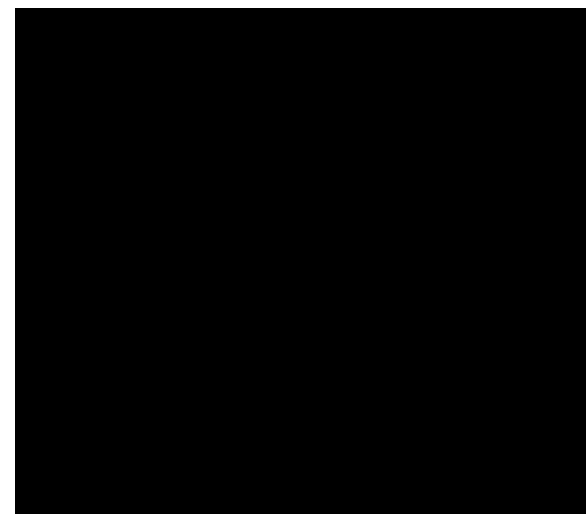

Scheme 1.

Preparation of Alkynyl Alcohols $\mathbf{7}$ and $\mathbf{8}$ 


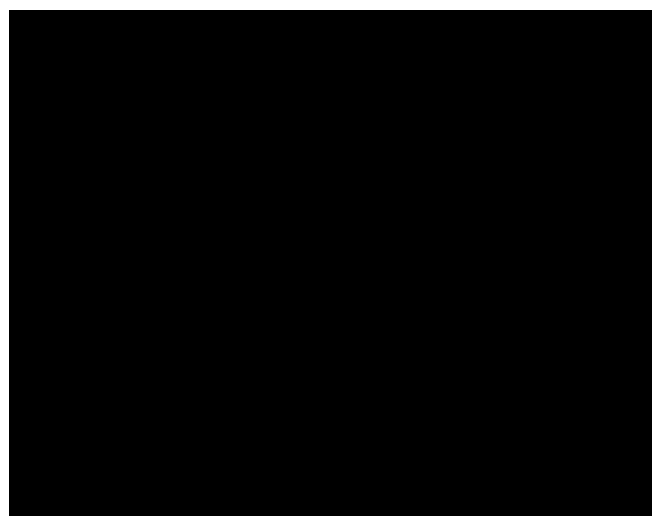

Scheme 2.

Synthesis of Diols 15a and 15b 


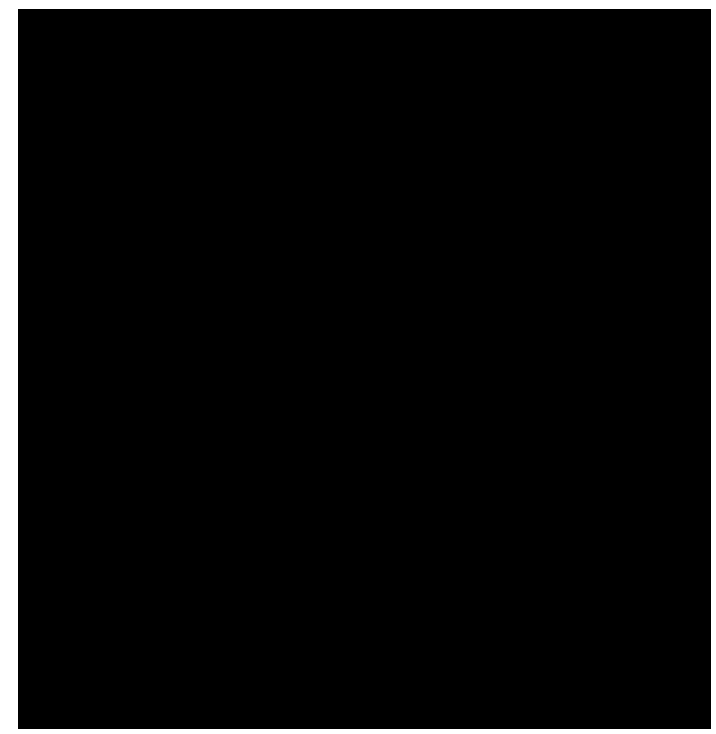

Scheme 3.

Synthesis of Diols 20a and 20b 


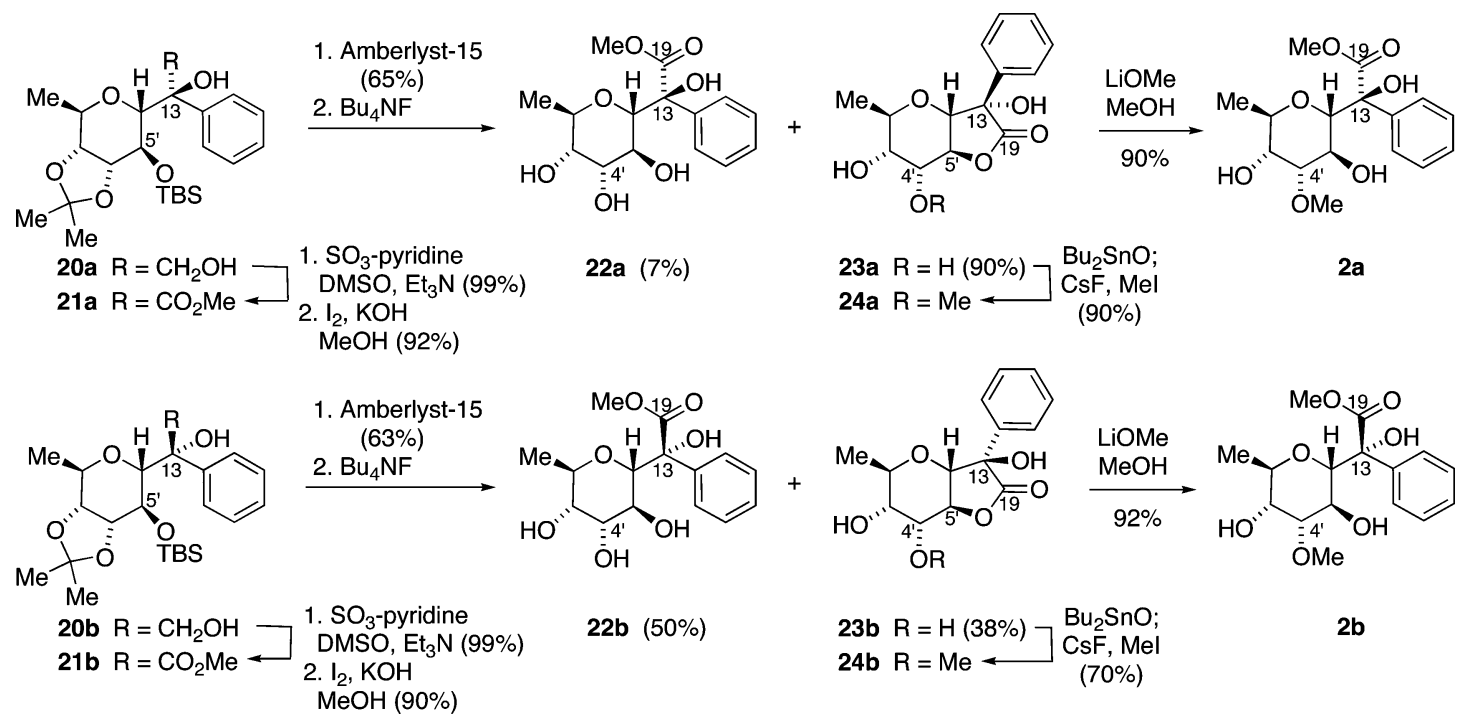

Scheme 4.

Conversion of Diols 20a and 20b to the Corresponding Altromycin Branched Glycoside Substructures $\mathbf{2 a}$ and $\mathbf{2 b}$ 


\section{Table 1}

Cycloisomerizations of Alkynyl Alcohols $\mathbf{7}$ and $\mathbf{8}$

\begin{tabular}{|c|c|c|c|c|}
\hline substrate & $\mathrm{R}_{3} \mathrm{~N}$ & solvent & products (ratio) $^{a}$ & combined yield (\%) \\
\hline 7 & DABCO & THF & $\mathbf{9 ,} \mathbf{1 0}(4: 1)$ & 33 \\
\hline 8 & $\mathrm{Et}_{3} \mathrm{~N}$ & THF & $\mathbf{1 1}, 12(7: 1)$ & 52 \\
\hline 8 & DABCO & THF & $\mathbf{1 1 , 1 2}(10: 1)$ & 68 \\
\hline 8 & $\mathrm{Et}_{3} \mathrm{~N}$ & toluene & $\mathbf{1 1}, \mathbf{1 2}(8: 1)$ & 64 \\
\hline 8 & DABCO & toluene & 11 (endo only) & $72^{b}$ \\
\hline
\end{tabular}

${ }^{a}$ Determined by ${ }^{1} \mathrm{H} \mathrm{NMR} \mathrm{(400} \mathrm{MHz).}$

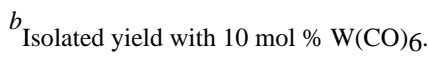

